\title{
A INCONSTITUCIONALIDADE DAS LEIS ESTADUAIS FISCALIZATÓRIAS DE PARTICIPAÇÕES GOVERNAMENTAIS
}

\author{
UNCONSTITUTIONALITY OF MEMBER STATES LAWS ON GOVERNMENT TAKES \\ SURVEILLANCE
}

Emerson Ademir Borges de Oliveira ${ }^{\text {ab }}$

\begin{abstract}
RESUMO: O presente artigo tem por escopo uma análise ampla acerca da constitucionalidade das leis dos Estados-Membros cuja pretensão seja a fiscalização das participações governamentais - dentre elas, os royalties -, principalmente no tocante à sua arrecadação e repasse. As participações governamentais, com o incremento das fontes de energia, estão se tornando importantes receitas dos Estados, o que não os coloca, no entanto, na posição de titulares de respectivo direito, devendo-se manter intactas as soluções constitucionais no que diz respeito a tal competência. A discussão perpassa pelo conceito de recursos minerais, competência dos entes federativos no tocante a tal temática, aspectos tributários e ajuizamento de ações de inconstitucionalidade em face de tais leis. O trabalho dedica-se, eminentemente, a um estudo doutrinário e jurisprudencial voltado para a hermenêutica constitucional e a análise do objeto questionado. Considerando-se, justamente, o ponto de partida da interpretação constitucional para aplicação em tal objeto, o método é dedutivo.
\end{abstract}

PALAVRAS CHAVE: Participações governamentais. Inconstitucionalidade. Leis estaduais. Fiscalização.

\begin{abstract}
The scope of this article is a comprehensive analysis on the constitutionality of the Member States laws whose claim is the government takes surveillance - including the royalties -, mainly about its storage and transfer. Government takes, with increasing of energy sources, are becoming important revenue to the member states, what does not authorize the interpretation of they are the holder of that rights and which call us to keep intact the constitutional authority. The discussion includes the concept of mineral resources, competence of federal entities, tax aspects and unconstitutionality claims against such laws. This paper is mainly devoted to a doctrinal and jurisprudence study, focused on constitutional hermeneutics and the analysis of the questioned object. Considering the constitutional interpretation as a guide point for the study of the object, the method is deductive.
\end{abstract}

KEYWORDS: Government takes. Unconstitutionality. Member States Laws. Surveillance.

\footnotetext{
a Mestre e Doutor em Direito do Estado pela Universidade de São Paulo. Pós-Doutorando em Direitos Humanos pela Universidade de Coimbra. Professor Assistente Doutor na Universidade de Marília nos Cursos de Graduação e Mestrado em Direito. Advogado. E-mail: borgesdeoliveira@usp.br

${ }^{\mathrm{b}}$ Artigo recebido em 14/04/2016 e aprovado em 08/06/2016
} 


\section{INTRODUÇÃO}

Participações governamentais (government takes), a teor do artigo $3^{\circ}$, III, do Decreto 2705/98, são "pagamentos a serem realizados pelos concessionários de atividades de exploração e produção de petróleo e de gás natural", que contemplam quatro modelos distintos previstos no contrato de concessão e no próprio edital de licitação dos blocos: bônus de assinatura; royalties; participação especial; pagamento pela ocupação ou retenção de área (art. 45 da Lei 9.478/97).

De acordo com o artigo 176 da Constituição Federal, os recursos minerais em geral se apresentam como um conjunto de bens pertencentes à União, destacando-se do solo, mas conferindo ao concessionário a propriedade do produto da lavra. O artigo 20, IX, por sua vez, escala entre os bens da União, os recursos minerais, inclusive os do subsolo. Por outra via, em conjunto ao produto da lavra, vem o encargo de arcar com contraprestações financeiras ao Estado ${ }^{c}$. Daí porque Menezello (2000), afirmar que as participações governamentais são "encargos que o concessionário deve pagar em virtude da exploração e da produção de petróleo", e também de gás natural.

Tais pagamentos têm por escopo compensar financeiramente o Estado pela exploração do bem, mormente em se tratando de produto de natureza não renovável. Isto é, tendo em vista a sua potencial degradação ambiental, guardam estreita relação com os princípios do poluidor pagador $^{\mathrm{d}}$ e do tributo verde (MACHADO, 2008, p.64).

\footnotetext{
São Paulo. Pós-Doutorando em Direitos Humanos pela Universidade de Coimbra. Professor Assistente Doutor na Universidade de Marília nos Cursos de Graduação e Mestrado em Direito. Advogado

c Artigo recebido em 14/04/2016 e aprovado em 19/09/2017

dos, com os encargos relativos ao pagamento dos tributos incidentes e das participações legais ou contratuais correspondentes.

d “O princípio do poluidor pagador justifica ainda a interessante interseção entre o Direito Administrativo e o Direito Financeiro a partir do reconhecimento, como visto acima e aqui reiterado, de que o Meio Ambiente constitui-se num patrimônio, é um bem econômico e, como tal, a utilização dos recursos naturais deve ser valorada e ser objeto de um preço. Ora, na medida em que, ao ser dada destinação econômica aos bens da Natureza, esta se transforma, se empobrece na sua pureza original (o que em última análise é poluição, na verdade o modo de viver da espécie humana e sua capacidade de intervir conscientemente na Natureza é que tem levado às mutações ambientais deletérias" (OLIVEIRA, 2005, p.495-496).
} 
Outrossim, as participações governamentais servem como importante instrumento de realização de políticas públicas, possibilitando que os entes federativos aufiram uma receita extra para o suprimento de suas necessidades. De um lado, assegura-se o interesse do concessionário, que, não mais sujeito a regime de monopólio (art. 177, V, CF), permite maiores investimentos externos para a extração do produto. De outro, compensa-se o Estado pela retirada de sua riqueza, com pagamentos maiores conforme a expansão do investimento (LEITE, 2009, p.531).

No processo de concessão, o bônus de assinatura, primeiramente, corresponde "ao montante ofertado pelo licitante vencedor na proposta para obtenção da concessão de petróleo ou gás natural, não podendo ser inferior ao valor mínimo fixado pela ANP no edital da licitação" (art. $9^{\circ}$ do Decreto 2705/98). Trata-se "de uma prestação devida pelo vencedor da licitação que teria a finalidade principal de 'recuperar os custos governamentais decorrentes do processo"' (OLIVEIRA, 2005, p.497). Ainda, de acordo com o artigo 10 do Decreto, os recursos provenientes do bônus de assinatura serão destinados à ANP.

Os royalties, por sua vez, "constituem compensação financeira devida pelos concessionários de exploração e produção de petróleo ou gás natural", a serem pagos mensalmente, tendo por base cada campo explorado, a partir do início da produção (art. 11 do Decreto 2705/98). Como estão atrelados à produção comercial, seu percentual é incerto, a depender de levantamento do quanto produzido (OLIVEIRA, 2005, p.497). São os royalties, além do valor mais substancial, os mais conectados à ideia de compensação pela extração e uso do produto proveniente das jazidas.

Já as participações especiais, também consideradas nítidas compensações financeiras pela exploração, constituem-se em receita extraordinária em casos de grande volume de produção ou de grande rentabilidade (art. 21 do Decreto 2705/98) (BUCHEB, 2007, p.271272). São, na realidade, royalties especiais e, por isso, possuem a mesma natureza.

Por fim, o pagamento pela ocupação ou retenção de áreas. Trata-se de pagamento já disposto no próprio edital e no contrato de concessão, pago anualmente em vista da utilização da área (artigo 28 do Decreto 2705/98). Como ressalta Oliveira (2005, p.498), trata-se de “"uma espécie de aluguel pela posse do domínio público em que se constitui a jazida' (superfície do bloco) objeto da concessão".

Frise-se que, em vista das características acima delineadas, os Estados e Municípios perceberão frutos decorrentes apenas dos royalties e das participações especiais. Isto porque 
apenas tais participações se encaixam no conceito do artigo $20, \S 1^{\circ}, \mathrm{CF}$, segundo o qual, aos Estados, Distrito Federal e Municípios, assegura-se participação no resultado da exploração de petróleo ou gás natural ou compensação financeira por essa exploração. E, como visto acima, o bônus de assinatura e o pagamento pela ocupação não derivam diretamente da própria exploração, mas da instrumentação para se explorar.

\section{TITULARIDADE DOS CRÉDITOS DECORRENTES DE PARTICIPAÇÕES GOVERNAMENTAIS, FISCALIZAÇÃO E INVASÃO LEGISLATIVA ESTADUAL}

\subsection{Notas Introdutórias}

De acordo com o artigo 18 do Decreto 2705/98, os royalties são apurados mensalmente pelos concessionários, tendo em vista cada campo, a partir da produção, "cabendo ao concessionário encaminhar para a Agência Nacional de Petróleo a demonstração da apuração de valores, bem como o comprovante de pagamento dos mesmos". Além disso, o artigo 19 do referido Decreto é inequívoco no sentido de que cabe à ANP a fiscalização da veracidade das informações prestadas pelo concessionário.

Outrossim, a distribuição dos recursos provenientes de tal fonte de receita cabe à Secretaria do Tesouro Nacional, do Ministério da Fazenda, de acordo com os cálculos sobre a parcela de cada beneficiário, como indicado pela ANP (art. 20 do Decreto 2705/98).

A mesma sistemática se aplica às participações especiais que, como dissemos, nada mais são do que um tipo específico de royalties. Por tal razão, resta claro, pela leitura dos artigos 25 e 26 do Decreto, que a arrecadação é destinada à ANP, igualmente responsável pela fiscalização dos dados enviados ${ }^{\mathrm{e}}$. Da mesma forma, os seus recursos são distribuídos pela STN, a partir das informações da ANP (art. 27).

\footnotetext{
e Art. 25. O valor da participação especial será apurado trimestralmente por cada concessionário, e pago até o último dia útil do mês subsequente a cada trimestre do ano civil, cabendo ao concessionário encaminhar à ANP um demonstrativo da apuração, em formato padronizado pela ANP, acompanhado de documento comprobatório do pagamento, até o quinto dia útil após a data de pagamento.

Art. 26. A seu critério, sempre que julgar necessário, a ANP poderá requerer do concessionário documentos que comprovem a veracidade das informações prestadas no demonstrativo da apuração.
} 
Ao depois, como ressaltado no artigo 29 do supracitado Decreto, as participações governamentais são pagas pelos concessionários com destinação da receita à Conta Única do Governo Federal, para - no caso dos royalties e das participações especiais -, somente após, serem repassadas pela STN com base nas informações da ANP ${ }^{f}$.

\subsection{Primeira discussão: a hermenêutica da expressão "recursos minerais" na Constituição}

A Constituição abre um espaço para discussão acerca da compreensão da expressão "recursos minerais", se estariam os mesmos a abarcar aqueles provenientes da exploração de "petróleo ou gás natural” ou se estes estariam descritos em um tipo específico da própria Carta Magna.

Na realidade, a depender da resposta ofertada, a questão acerca da fiscalização dos Estados torna-se rapidamente respondida ou merecerá maiores digressões, consoante teor do artigo 23, XI, CF:

Art. 23. É competência comum da União, dos Estados, do Distrito Federal e dos Municípios:

(...)

XI - registrar, acompanhar e fiscalizar as concessões de direitos de pesquisa e exploração de recursos hídricos e minerais em seus territórios (g.n.);

Veja-se, a início, que a extensão da expressão "recursos minerais" poderá retirar ou possibilitar aos Estados, Distrito Federal e Municípios a fiscalização dos recursos provenientes da exploração e produção de petróleo e gás natural. Pois, evidentemente, a restrição já tem o condão de ter por inconstitucionais, de plano, todas as leis estaduais que carreiam tais pretensões, a exemplo da Lei 6.557/2004 de Alagoas, Lei 5.854/2006 de Sergipe, Lei

\footnotetext{
f Art. 29. O pagamento das participações governamentais será efetuado pelos concessionários nos prazos estipulados neste Decreto, em moeda corrente ou mediante transferência bancária e as receitas correspondentes serão mantidas na Conta Única do Governo Federal, enquanto não forem destinadas para as respectivas programações.

Art. 35. Os recursos provenientes dos pagamentos dos royalties e da participação especial serão distribuídos pela STN, nos termos da Lei $\mathrm{n}^{\circ}$ 9.478, de 1997, e deste Decerto, com base nos cálculos dos valores devidos a cada beneficiário, fornecidos pela ANP, e, nos casos dos Estados e Municípios, serão creditados em contas específicas de titularidade dos mesmos, junto ao Banco do Brasil S.A.
} 
8.501/2007 do Espírito Santos, Lei 10.350/2007 da Bahia e, finalmente, Lei 15.833/2015 de São Paulo, bem como respectivos Decretos Regulatórios, inconstitucionais por arrastamentog

Por outra via, a compreensão dos recursos provenientes de petróleo e gás natural dentro da expressão recursos minerais dará continuidade à discussão, abarcando outras temáticas como a competência legislativa e material da União e dos Estados.

Em vista de se tratar de um estudo de amplas pretensões, teceremos discussões a partir das duas vias.

Para os que advogam pela primeira corrente, o registro, acompanhamento $e$ fiscalização, previstos no artigo 23, XI, destinar-se-iam exclusivamente a recursos hídricos e minerais, o que não permite a inclusão hermenêutica no tocante aos recursos provenientes da exploração de petróleo e gás natural.

Isso porque a Constituição, noutro momento, fez tal clara distinção, destinando o artigo 176 aos recursos minerais em geral, ao passo em que restou inequívoco que o artigo 177 destinava-se, especificamente, ao petróleo e gás natural.

Daí porque o artigo 176 falar em “jazidas, em lavra ou não, e demais recursos minerais e os potenciais de energia hidráulica", que constituem "propriedade distinta da do solo, para efeito de exploração ou aproveitamento, e pertencem à União, garantida ao concessionário a propriedade do produto da lavra".

Enquanto isso, prevê, no artigo seguinte, que "a pesquisa e a lavra das jazidas de petróleo e gás natural e outros hidrocarbonetos fluidos" (art. 177, I) constitui monopólio da União, logicamente relativizado pela Emenda Constitucional 49/2006. Assim, por interpretação lógica, não haveria sentido em tratar o petróleo e o gás natural de maneira distinta dos demais recursos minerais se o legislador constituinte não o quisesse realmente fazê-lo.

A partir desse ponto, a consonância entre o artigo 177 da CF com o supracitado artigo 23, XI, perderia sentido, razão pela qual este estaria mais afinado com o artigo 176.

E não é só.

O artigo 20, $1^{\text {o }}$, da CF, ao abarcar o direito de participação dos Estados nos resultados da exploração, expressamente diferencia aquela decorrente de petróleo e gás natural dos demais recursos minerais:

Art. 20. São bens da União:

g Consoante precedente fixado na ADI 2.995, rel. Min. Celso de Mello, julg. 13.12.2006. 
(...)

$\S 1^{\circ}$ É assegurada, nos termos da lei, aos Estados, ao Distrito Federal e aos Municípios, bem como a órgãos da administração direta da União, participação no resultado da exploração de petróleo ou gás natural, de recursos hídricos para fins de geração de energia elétrica e de outros recursos minerais no respectivo território, plataforma continental, mar territorial ou zona econômica exclusiva, ou compensação financeira por essa exploração (g.n.).

Consoante o grande mestre da hermenêutica pátria, Maximilano (1993, p.250), "devem-se compreender as palavras [da lei] como tendo alguma eficácia", de forma que o objeto legal não seja visto como detentor de expressões inúteis.

E a razão, neste caso, é muito simples: petróleo e gás natural não podem ser enquadrados, quanto à sua ontologia, na categoria de minérios.

De acordo com a clássica definição de Nickel e Grice (Apud ATENCIO, 2015, p.144), uma espécie mineral é i) um sólido homogêneo; ii) formada por um processo geológico; iii) com composição química e estrutura cristalina definidas. Tais características facilmente excluem da espécie mineral o petróleo e o gás natural.

O petróleo é formado a partir de um processo de decomposição de matéria orgânica, de composição química muito variável, classificado como um fóssil líquido. Por não possuir composição química específica e nem arranjo atômico ordenado, além de ser formado por carbono orgânico, é patente na comunidade científica que o petróleo não é um mineral (ULBRA, 2015). Da mesma forma, o gás natural é um combustível fóssil, com composição extremamente variável, a partir dos fatores externos. Logo, também carece de composição química específica e estrutura definida, além de permanecer em estado gasoso à temperatura ambiente e pressão atmosférica. Assim, nada há, na ciência mineral que possa auxiliar na classificação do petróleo e do gás natural enquanto recursos minerais.

Evidentemente, se assim o diz a ciência, não poderia a Constituição pretender o oposto. E não o fez.

Nesse sentido, o magistério de Bercovici (2010, p.293):

(...) a própria Constituição institui um regime diferenciado ao petróleo e ao gás natural nos seus artigos $20, \S 1^{\circ}$, que trata da repartição dos resultados da exploração dos recursos minerais entre a União e os demais entes da Federação, distinguindo expressamente o petróleo e o gás natural dos demais recursos minerais, e 177, que estrutura o monopólio da União sobre o petróleo e o gás natural (além dos minérios nucleares) (g.n.). 
Insta frisar, a propósito, que este entendimento encontra agasalho em decisão do Pretório Excelso na Ação Direta de Inconstitucionalidade 3.273, compreendendo que as atividades descritas no artigo 177 são específicas e exclusivas da União:

Os preceitos veiculados pelos $\$ 1^{\circ}$ e $\$ 2^{\circ}$ do art. 177 da Constituição do Brasil são específicos em relação ao art. 176, de modo que as empresas estatais ou privadas a que se refere o $\S 1^{\circ}$ não podem ser chamadas de "concessionárias".

Trata-se de titulares de um tipo de propriedade diverso daquele do qual são titulares os concessionários das jazidas e recursos minerais a que respeita 0 art. 176 da Constituição do Brasil ${ }^{\mathrm{h}}$ (g.n.).

Isso significa que as atividades referentes à lavra de petróleo e gás natural não apenas constituem monopólio exclusivo da União, mas também monopólio amplo, no tocante à fiscalização, legislação e execução. Logo, o artigo 23, XI, CF, ao abarcar a temática dos recursos minerais, em momento algum estende tal poder dos Estados e Municípios para as atividades do art. 177.

Disso decorre que, não havendo tal direito, Estados poderão exercer poder fiscalizatório apenas na existência de instrumento vinculado de cooperação, nos termos do artigo $8^{\circ}$, VII, da Lei 9.478/97'. Evidente, a fiscalização mediante convênios com Estados é faculdade conferida à Agência Nacional de Petróleo e tem o único intuito de auxiliar a própria ANP, nos ditames das normas federais, sem possibilidade de qualquer inovação por parte do ente federativo estatal.

Melhor dizendo, tais cooperações devem estar aptas a promover racionalmente o princípio da eficiência administrativa (art. 37, caput), tido como aquele que pressupõe o desenvolvimento da qualidade e da presteza, no anseio por resultados positivos, atuando na Administração Pública para melhoria do rendimento funcional, da perfeição e da rapidez no atendimento dos interesses da coletividade (DI PIETRO, 2002, p.83).

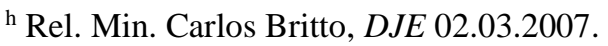

i Art. 8 A ANP terá como finalidade promover a regulação, a contratação e a fiscalização das atividades econômicas integrantes da indústria do petróleo, do gás natural e dos biocombustíveis, cabendo-lhe: (...) VII fiscalizar diretamente e de forma concorrente nos termos da Lei $\mathbf{n}^{\mathbf{0}} \mathbf{8 . 0 7 8}$, de 11 de setembro de 1990, ou mediante convênios com órgãos dos Estados e do Distrito Federal as atividades integrantes da indústria do petróleo, do gás natural e dos biocombustíveis, bem como aplicar as sanções administrativas e pecuniárias previstas em lei, regulamento ou contrato (g.n.)
} 


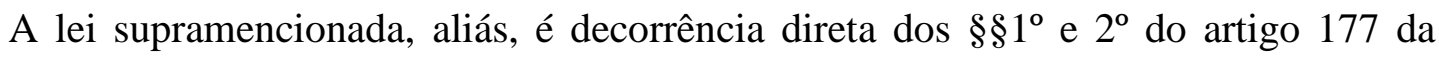
Constituição Federal, que, na relativização do monopólio, permite que a União contrate com outras empresas as atividades previstas nos incisos I a IV, dentre eles a pesquisa e lavra das jazidas de petróleo e gás natural e outros hidrocarbonetos fluídos, observadas as condições estabelecidas em $l e i^{\mathrm{j}}$, completando em absoluto o sentido das normas constitucionais (MARQUES NETO, 2010, p.311).

Nota-se, ademais, que consoante inciso III do mencionado $\S 2^{\circ}$, as atribuições do órgão regulador - ANP - são amplamente discorridas pelo artigo $8^{\circ}$ da Lei 9.478/97, restando evidente que, a partir disso, por convênios de cooperação, pouco caberá aos Estados, devendo estes seguir a linha das digressões federais, sem nenhuma perspectiva inovatória, sob pena de malferimento tanto da Lei quanto da Constituição, que determina que as atribuições decorrerão da lei federal.

Mais ainda: ser a Agência Nacional de Petróleo uma agência reguladora federal, decorrente do artigo $177, \S 2^{\circ}$, III, ressalta o fato de que a propriedade do bem, e os poderes dele decorrentes, são exclusividade da União.

Mesmo o incisivo VII do artigo $8^{\circ}$ da Lei do Petróleo, antes de possibilitar o estabelecimento de cooperação, deixa claro que cabe à ANP a fiscalização direta das atividades integrantes da indústria do petróleo, do gás natural e dos biocombustíveis, cabendo-lhe aplicar sanções administrativas e pecuniárias previstas em lei, regulamento ou contrato. Em nenhum momento, a lei atribui - e nem poderia - a qualquer outro ente federativo a fiscalização da atividade mencionada.

Aliás, nesse ponto, deixe-se bem delineado que a competência concorrente a que alude referido inciso se dá tão somente nos casos de lesão a direito de consumo, o que não guarda qualquer conexão com a questão aqui discutida ${ }^{\mathrm{k}}$. Este tipo de competência, em realidade, relaciona-se, em geral, com a comercialização de combustíveis e atividades correlatas.

Ora, na celebração dos referidos convênios, deve-se ter em mente que a competência para o estabelecimento dos procedimentos fiscalizatórios continua sendo da União, que os exerce pela ANP, inexistindo, por afronta ao princípio federativo, a possibilidade de outros entes, ainda que conveniados, criarem novos procedimentos ou competências, mas apenas

\footnotetext{
j $\S 2^{\circ}$ A lei a que se refere o $\S 1^{\circ}$ disporá sobre: I - a garantia do fornecimento dos derivados de petróleo em todo o território nacional; II - as condições de contratação; III - a estrutura e atribuições do órgão regulador do monopólio da União.

${ }^{\mathrm{k}}$ Consoante artigo 55 do Estatuto de Defesa do Consumidor.
} 
receber da União aqueles já estabelecidos em lei e dissertados no próprio convênio. O convênio não serve, sob pena de afronta ao princípio da legalidade, como supedâneo normativo para a criação de novas competências.

O que se possibilita - frise-se - é a conjugação de esforços, mediante a transferência de competências executórias específicas para os Estados e Distrito Federal. Daí porque, mesmo conveniados, Estados não poderiam, como fazem algumas leis estaduais, exigir documentação além daquela já exigida pela própria ANP, uma vez que inexiste transferência normativa.

Tampouco, é possível a transferência do núcleo fiscalizatório, cuja atividade é de interesse expresso da União, mas apenas de atividades satelitárias, geralmente aquelas em que o Estado possui mais facilidade de exercício do que a ANP. Como delegar ocasiona a transferência de determinada competência, inadmitir-se-ia a delegação por completo ou do núcleo decisório, pois isso implicaria não apenas na perda da própria competência, mas em afronta à Lei do Petróleo e ao monopólio da União. Até porque, na prática, quem delega deixa de exercer aquela parcela da função. E delegar deve ter como escopo a efetivação do princípio da eficiência e não a geração de múltiplos exercícios idênticos que mais dificultam do que auxiliam a pretensão legal.

Logo, diante deste posicionamento: i) Estados e Municípios não possuem competência fiscalizatória quanto às atividades de lavra de hidrocarbonetos, mas apenas de recursos minerais; ii) a competência para tanto é exclusiva da União, que a exerce por meio da ANP; iii) a ANP poderá estabelecer convênios com Estados e Distrito Federal - não com Municípios apenas para facilitar atividades executórias de fiscalização, sem qualquer possibilidade de inovação legislativa nas raias fiscalizatórias por estes entes.

\subsection{Entendimento diverso: aceitação da amplitude da expressão "recursos minerais"}

A despeito da substancialidade dos argumentos acima alongados, não se ignora a presença difusa de entendimento diverso, segundo o qual a competência do artigo 23, XI, CF, concorrente entre União, Estados, Distrito Federal e Municípios, permitiria a fiscalização dos Estados na seara da lavra de hidrocarbonetos, a partir de uma versão expansiva do termo recursos minerais. 
Decorreria daí, por exemplo, que o artigo 176, ao tratar das jazidas de recursos minerais, acolheria também as atividades de lavra de petróleo e gás natural, não mais exclusivas do artigo 177.

Esta posição é defendida, entre outros, por Bucheb (2007, p.9):

É importante ressaltar que em que pese à definição clássica atribuída ao vocábulo "mineral": material sólido natural, inorgânico, de composição química definida e estrutura interna regular, que constitui a litosfera, a incidência da regra contida no art. $176 \mathrm{da} \mathrm{CF} / 88$ alcança, inequivocamente, as jazidas de petróleo e gás natural. Nessa linha Barbosa (2004) assinala que "o Código de Minas, promulgado pelo Decreto n 26.642, de 10 de julho de 1934, estabelecia, em seu Título VIII - Das Jazidas de Petróleo e Gás Natural - as normas básicas que disciplinavam as atividades de pesquisa e de lavra dessas jazidas. As rochas betuminosas e piro-betuminosas, bem como o petróleo e o gás natural, eram classificadas, respectivamente, como minerais das Classes IX e X (Capítulo I - Jazidas e Minas: sua classificação e aproveitamento, art. $2^{\circ}$ ). Por sua vez, o Código de Minas, promulgado pelo Decreto-lei $\mathrm{n}^{\circ} 1.985$, de 29 de janeiro de 1940, que revogou e substituiu integralmente o Código anterior, manteve, todavia, a mesma classificação antes conferida ao petróleo e ao gás. (...) fica, assim, evidenciado que o nosso Direito sempre dedicou, historicamente, ao petróleo e ao gás natural o mesmo tratamento jurídico aplicável aos recursos minerais propriamente ditos".

A despeito da vetusta observação acerca do Código de Minas, bem como da atécnica posição quanto à significação dos termos, passamos a desenvolver a argumentação a partir de tal perspectiva.

Num primeiro instante, cumpre mencionar que, nos termos do artigo 22, XII, CF, compete privativamente à União legislar sobre jazidas, minas, outros recursos minerais $e$ metalurgia. No âmbito da legislação concorrente - art. 24 - nada se afirma acerca da competência para tratar de temáticas que interessam à presente análise. Outrossim, o artigo 20 estabelece como bem da União os recursos minerais, inclusive os do subsolo.

A despeito disso, o $\$ 1^{\circ}$ do mesmo artigo 20 assegura, nos termos da lei evidentemente federal -, aos Estados, Distrito Federal e Municípios, “a participação no resultado da exploração de petróleo ou gás natural (...) e de outros recursos minerais no respectivo território, plataforma continental, mar territorial ou zona econômica exclusiva, ou compensação financeira por essa exploração" (g.n.).

Em complementação, o artigo 23, ao tratar da competência material comum da União, Estados, Distrito Federal e Municípios, estabelece, em seu inciso XI, o registro, acompanhamento e fiscalização das "concessões de direitos de pesquisa e exploração de 
recursos hídricos e minerais em seus territórios", de forma a resguardar os respectivos interesses.

Ocorre que o estabelecimento de participações governamentais, como forma de remediar os demais entes federativos, bem como a atribuição de competência fiscalizatória, como previstos na Constituição não coaduna com o entendimento maximizado de estabelecimentos legislativos, como têm pretendido os Estados, nos termos das leis já apontadas.

Primeiro, em face do claro interesse nacional sobre tais lavras, amparado pela eloquência do artigo 20 ao estabelecer que tais bens são da União. Segundo, em face do artigo 22, que designa tais temáticas como de legislação privativa da União, sem qualquer menção do artigo 24, em inequívoco silêncio eloquente. Apenas a competência de registro, acompanhamento e fiscalização de recursos minerais é, na leitura constitucional, comum a todos os entes federativos.

Como lembra Tavares (2013, p.876), é “o art.22 da Constituição brasileira o locus das competências privativas da União. Sua simples leitura é capaz de conduzir à conclusão de que se trata de um rol extenso e centralizador das mais relevantes matérias".

E se já não bastasse o conceito de matéria privativa da União, o próprio artigo 22, em seu parágrafo único, deixa claro que os Estados somente poderão legislar sobre tais matérias, em questões específicas, quando autorizados por Lei Complementar ${ }^{1}$.

Para manter a coerência legislativa, nota-se que toda a regulamentação acerca da pesquisa e lavra de hidrocarbonetos é da seara federal: Leis $n^{\circ}$ 9.478/1997, 9.847/1999, $12.276 / 2010$ e $12.351 / 2010^{\mathrm{m}}$. Outrossim, inexiste autorização por lei complementar para que os Estados possam, em temas específicos, tratar de tais matérias. Logo, não poderia ser regulada pelos Estados e Distrito Federal.

\footnotetext{
1 “A competência privativa da União para legislar está listada no art. 22 da CF (...) Os assuntos mais relevantes e de interesse comum à vida social no País nos seus vários rincões estão enumerados no catálogo do art. 22 da CF. O parágrafo único do art. 22 prevê a possibilidade de lei complementar federal vir a autorizar que os Estadosmembros legislem sobre questões específicas de matérias relacionadas no artigo. Trata-se de mera faculdade aberta ao legislador complementar federal. Se for utilizada, a lei complementar não poderá transferir a regulação integral de toda uma matéria da competência privativa da União, já que a delegação haverá de referir-se a questões específicas. Nada impede que a União retome sua competência, legislando sobre o mesmo assunto a qualquer momento, uma vez que a delegação não se equipara à abdicação de competência" (MENDES et al, 2008, p.820). ${ }^{m} \mathrm{E}$ como ressaltou o AGU na ADI 4606: "Relativamente às jazidas, minas e outros recursos minerais, José Afonso da Silva afirma que a competência da União para legislar sobre a matéria já foi exercida, apontando, a respeito, o Código de Minas (Decreto-Lei no 1.985/40), substituído pelo Código de Mineração (Decreto-Lei no 227/67), que atribui à União a competência 'para administrar os recursos minerais, a indústria de produção mineral e a distribuição, o comércio e o consumo de produtos minerais '”.
} 
Como ressaltou o Advogado-Geral da União em manifestação na ADI 4606: “Ocorre que a competência administrativa para registrar, acompanhar e fiscalizar ditas concessões não autoriza a edição de lei estadual, distrital ou municipal sobre o tema, sob pena de invasão da competência legislativa atribuída, com exclusividade, à União".

A despeito de o artigo 176 da $\mathrm{CF}$ garantir ao concessionário a propriedade do produto da lavra, em momento algum transferiu a propriedade dos recursos minerais, isto é, das jazidas, para outro ente, mantendo-o, na linha do artigo 20, IX, sob o domínio da União. E, mesmo assim, como ressalta Grau (2013, p.1851-1852), a propriedade sobre o produto da lavra "não é plena, mas relativa, visto que a comercialização de ambos é administrada pela União, através de uma autarquia sua, hoje a Agência Nacional do Petróleo".

Ao depois, o próprio STF, no leading case ADI 855, declarou inconstitucional lei estadual do Paraná que pretendia abarcar regulamentação de GLP:

Ação Direta de Inconstitucionalidade. 2. Lei 10.248/93, do Estado do Paraná, que obriga os estabelecimentos que comercializem Gás Liquefeito de Petróleo - GLP a pesarem, à vista do consumidor, os botijões ou cilindros entregues ou recebidos para substituição, com abatimento proporcional do preço do produto ante a eventual verificação de diferença a menor entre o conteúdo e a quantidade líquida especificada no recipiente. 3. Inconstitucionalidade formal, por ofensa à competência privativa da União para legislar sobre o tema (CF/88, arts. 22, IV, 238). 4. Violação ao princípio da proporcionalidade e razoabilidade das leis restritivas de direitos. 5. Ação julgada procedente (ADI 855, rel. Min. Octavio Gallotti, julg. 06.03.2008, g.n.).

Assim, mesmo olvidando a clara distinção constitucional entre recursos minerais e petróleo e gás natural, os Estados estariam sob a vedação do artigo 22 quanto à regulamentação da matéria ${ }^{\mathrm{n}}$. E, mesmo na existência de lei complementar autorizadora, estariam vinculados aos termos desta, da matéria específica e da própria legislação federal geral ${ }^{\circ}$.

\footnotetext{
${ }^{n}$ Conforme manifestação do Advogado-Geral da União na ADI 4606: "Isso porque, muito embora seja assegurada aos Estados, ao Distrito Federal e aos Municípios participação nos resultados da exploração de recursos minerais e de potenciais energéticos, ou a compensação financeira por essa exploração, podendo, ainda, fiscalizar os instrumentos de concessão das referidas atividades, tal faculdade deve ser exercida nos estritos termos da legislação federal pertinente (artigo $20, \S 1^{\circ}$, da Constituição)".

o Como ensina Almeida (2007, p.116), os entes estatais ao "exercerem a fiscalização das atividades dos concessionários credenciados a explorar recursos hídricos e minerais haverão de observar necessariamente a legislação federal".
} 


\subsection{A natureza jurídica das participações governamentais e a competência dos entes} federativos

Em algumas das leis mencionadas, há menção de lançamento por parte do Estado dos valores apurados, se supostamente discordantes dos declarados pelos concessionários, com a consequente inscrição em dívida ativa e execução dos mesmos.

Veja-se, a propósito, os artigos $6^{\circ}, 7^{\circ}, 8^{\circ}, 9^{\circ}, 11$ e 13 da Lei Estadual Paulista 15.833/2015:

\section{CAPÍTULO IV}

\section{DA APURAÇÃO E DO PAGAMENTO DAS COMPENSAÇÕES FINANCEIRAS E DAS PARTICIPAÇÕES GOVERNAMENTAIS}

Artigo $6^{\circ}$ - As pessoas relacionadas no artigo $2^{\circ}$ desta lei efetuarão o pagamento das compensações financeiras e das participações governamentais na forma e nos prazos estabelecidos pela legislação federal, ficando sujeito à homologação pela autoridade administrativa estadual competente.

Artigo $7^{\mathbf{0}}$ - Constatado o não recolhimento na data aprazada pela legislação federal, bem como no caso de apuração de inconsistências no valor declarado pelo sujeito passivo, a SEFAZ provocará a ANP para que tome as providências cabíveis.

Artigo $8^{\mathbf{0}}$ - Decorrido o prazo de 60 (sessenta) dias contados da data da cientificação de que trata o artigo $7^{\circ}$ desta lei, a SEFAZ poderá efetuar o lançamento dos valores apurados, caso em que o recolhimento poderá ser realizado diretamente ao Estado de São Paulo.

Artigo $9^{\mathbf{0}}$ - $\mathrm{O}$ valor relativo a compensações financeiras ou participações governamentais declarado e não pago poderá ser inscrito na Dívida Ativa após 90 (noventa) dias contados do vencimento, independentemente de lavratura de Auto de Infração e Imposição de Multa.

Artigo 11 - Constatada infração a qualquer dispositivo da legislação, será lavrado Auto de Infração e Imposição de Multa por Agente Fiscal de Rendas. Artigo 13 - Lavrado o Auto de Infração e Imposição de Multa, terão início, na forma estabelecida pela SEFAZ, os procedimentos de cobrança administrativa, devendo o autuado ser notificado para, no prazo de 30 (trinta) dias, recolher o débito ou apresentar defesa por escrito.

$\S 1^{\circ}$ - Decorrido o prazo previsto no "caput" deste artigo sem que haja recolhimento ou acordo de parcelamento do débito ou apresentação de defesa, o débito será inscrito na Dívida Ativa.

$\S 2^{\circ}$ - O processo administrativo terá início com a apresentação da defesa de que trata o "caput" deste artigo e, no que couber, seguirá a legislação relativa ao processo administrativo tributário estadual. 
A leitura dos mencionados dispositivos leva à conclusão de que o Estado considera as participações governamentais como uma receita tributária de sua competência, por serem a ele direcionadas.

A lei, neste ponto, é teratológica.

As lições ausentes ao legislador paulista, no caso, devem ser buscadas no direito financeiro, mormente na Lei 4.320/64 e no próprio CTN. Participações governamentais, em primeiro lugar, não equivalem a impostos, taxas, contribuições de melhoria ou qualquer outra espécie tributária.

Como especifica o artigo $9^{\circ}$ da Lei 4.320/64, "tributo é receita derivada instituída pelas entidades de direito público". Isto é, deriva do patrimônio do particular e não do aproveitamento de um bem público, como a lavra de hidrocarbonetos, ocasião em que a receita é classificada como originária ${ }^{\mathrm{p}}$.

Ademais, tributo possui a natureza de compulsoriedade. É patente a lição de Paulsen (2014, p.35):

\begin{abstract}
A adequada consideração do traço da compulsoriedade faz com que não se caracterizem como tributárias as receitas patrimoniais relativas ao uso ou à exploração de bens públicos em caráter privado (taxa de ocupação de terreno de marinha e compensação financeira pela exploração de recursos minerais), porquanto, nestes casos, não há compulsoriedade na constituição do vínculo, mas adesão a um regime remuneratório ${ }^{q}$ (g.n.).
\end{abstract}

Evidentemente que, adentrando à temática do caixa estatal, as participações governamentais constituem receitas. Todavia, como demonstrado, não são receitas decorrentes do exercício do poder por parte do Estado. São auferidas pela União, por intermédio da ANP, armazenadas na STN e, posteriormente, transferidas aos Estados e Municípios, consoante visto

\footnotetext{
$\mathrm{p}$ "Embora os recursos naturais da plataforma continental e os recursos minerais sejam bens da União (CF, art. 20, V e IX), a participação ou compensação aos Estados, Distrito Federal e Municípios no resultado da exploração de petróleo, xisto betuminoso e gás natural são receitas originárias destes últimos entes federativos (CF, art. 20, § $1^{\circ}$ )" (MS 24.312, Rel. Min. Ellen Gracie, julg. 19.02.2003). No mesmo sentido: RE 228.800, rel. Min. Sepúlveda Pertence; AIAgR 453.025-1, rel. Min. Gilmar Mendes.

${ }^{q}$ No caso das participações governamentais, o que se tem é preço público: "O artigo 20, inciso IX, da Constituição Federal estabelece que são bens da União os recursos minerais, inclusive os do subsolo. Em seu artigo 176, a Carta da República dispõe que os recursos minerais constituem propriedade distinta da do solo, e confere, expressamente, à União os efeitos de exploração e aproveitamento. Dessa forma, a Administração Pública pode conferir a exploração ou aproveitamento dos recursos minerais ao uso especial de particulares, concessionários ou não de serviços públicos, por mais de três formas administrativas: autorização de uso, permissão de uso e concessão de uso. Não há qualquer óbice constitucional que impeça a União de permitir ao particular a utilização de seus recursos minerais, inclusive os do subsolo, mediante remuneração pelo uso. É pacífico o entendimento da doutrina e dos Tribunais no sentido de que a receita é um preço público" (ADI 2.586, rel. Min. Carlos Velloso).
} 
no item 1.1. Isto porque, como vimos, o dono do bem é a União e é com este ente que se estabelece a relação jurídica. Logo, inexiste possibilidade de exigência por parte dos Estados diretamente dos concessionários de um bem público da União.

Nesse sentido, explana Oliveira (2006, p.99): "Há receitas denominadas de transferidas, porque, embora provindas do patrimônio particular (a título de tributo), não são arrecadadas pela entidade política que vai utilizá-las”.

Ao depois, o fato de as participações governamentais configurarem receitas originárias não autoriza a interpretação de que podem ser diretamente cobradas ou inscritas em dívida ativa, justamente porque não podem ser cobradas, a despeito da existência a figura da dívida ativa não-tributária (art. 39, §2º , da Lei 4.320/64 ${ }^{\text {) }}$. Sendo a compensação de titularidade expressa da União, apenas a própria pode ser sujeito ativo de eventual cobrança pelo não pagamento.

O fato de ter o STF entendido, no MS 24.312, que a competência para fiscalização dos recursos provenientes de royalties é do Tribunal de Contas do Estado, e não do TCU, é, na realidade, uma lógica decorrente do fato de que para os Estados, as transferências são receitas. E, sendo receita do Estado, provindas de transferência obrigatória, devem ser fiscalizadas pelos órgãos de controle deste (art. 70 c.c. 75, CF). Nada mais. Não se extrai daí que os Estados possam conduzir a cobrança direta de tais receitas, senão percebê-las por transferência da União.

$\mathrm{Na}$ realidade, se os Estados entenderem que os valores pagos são menores do que aqueles realmente devidos, deverão se dirigir à ANP, seja para requisitar os documentos que, por exigência legal, já são a ela apresentados, seja para peticionar acerca das razões pela qual entende que pode estar ocorrendo sonegação de valores, consoante artigo $8^{\circ}$, VII, da Lei do Petróleo.

Logo, ainda que se entenda que a terminologia recursos minerais abarca a exploração de petróleo e gás natural, conclui-se: i) apenas a União é competente para legislar sobre a temática; ii) a União poderá autorizar, por lei complementar, que Estados legislem acerca de

\footnotetext{
r “§ $2^{\circ}$ - Dívida Ativa Tributária é o crédito da Fazenda Pública dessa natureza, proveniente de obrigação legal relativa a tributos e respectivos adicionais e multas, e Dívida Ativa não Tributária são os demais créditos da Fazenda Pública, tais como os provenientes de empréstimos compulsórios, contribuições estabelecidas em lei, multa de qualquer origem ou natureza, exceto as tributárias, foros, laudêmios, alugueis ou taxas de ocupação, custas processuais, preços de serviços prestados por estabelecimentos públicos, indenizações, reposições, restituições, alcances dos responsáveis definitivamente julgados, bem assim os créditos decorrentes de obrigações em moeda estrangeira, de subrogação de hipoteca, fiança, aval ou outra garantia, de contratos em geral ou de outras obrigações legais".
} 
temáticas específicas e em obediência estrita à legislação federal; iii) a possibilidade de fiscalização por parte dos Estados e Municípios não se coaduna com extensão inovadora dos poderes fiscalizatórios por parte destes, salvo na hipótese do item ii, e, ainda assim, amarradas pelas diretrizes da legislação federal, não podendo os Estados inovar em tal temática; iv) por constituírem receitas decorrentes de transferência da União, titular do bem, não estão os Estados autorizados a promover inscrição em dívida ativa, execução das quantias, suposições do quantum devido, bem como outras atividades indiretas para forçar os concessionários a aderirem ao valor que os Estados entendem como devidos; v) o canal legal para os Estados que entenderem que os valores estão sendo sonegados é a ANP, para requisitar documentos e também para explicitar suas razões, a fim de que esta tome as medidas cabíveis, a teor do artigo $8^{\circ}$ da Lei 9.478/97.

\section{SOBRE A POSSIBILIDADE DE CRIAÇÃO DE TAXAS SUBSTITUTIVAS PELOS ENTES FEDERADOS E A RESERVA DE MATÉRIA À UNIÃO.}

A presente análise tem por escopo, evidentemente, a consideração de que a expressão recursos minerais abarca a lavra de hidrocarbonetos, pois, do contrário, inexistiria para os Estados qualquer interesse na questão.

Alguns Estados pretenderam, como forma de compensar a perda decorrente do rearranjo de royalties, a criação de Taxas de Fiscalização das atividades petrolíferas, a exemplo do Projeto de Lei 1877/2012 do Estado do Rio de Janeiro que "Institui a Taxa de Controle, Monitoramento e Fiscalização das Atividades de Pesquisa, Lavra, Exploração e Aproveitamento de Petróleo e Gás - TFPG - e o Cadastro Estadual de Controle, Monitoramento e Fiscalização das Atividades de Pesquisa, Lavra, Exploração e Aproveitamento de Recursos Minerários - CERM".

Referido Projeto foi integralmente vetado pelo Governador do Estado do Rio de Janeiro, por aduzir que a competência para criação da mesma seria reservada à Chefia do Executivo, em face da implicação no aumento de despesas. Além disso, o projeto consideraria fato gerador da TFPG a venda ou transferência do petróleo ou gás, o que é inadmitido por ser tal fato gerador típico da espécie imposto, consoante artigo 16 do CTN. Ao passo em que a taxa 
pressupõe uma atuação do Poder Público, específica e divisível ou o exercício regular do poder de polícia (art. 77, CTN).

Ocorre que, como visto acima, a matéria deita sua competência na União, cabendo aos Estados atividades meramente materiais de fiscalização, nos termos da legislação federal ${ }^{\text {s. }}$ Por evidente, sendo o tributo decorrência coercitiva de $l e i$, somente poderá ser instituído, neste caso, por lei federal, diante da reserva de competência da União. Deve-se lembrar que as atividades fiscalizatórias eventuais dos Estados derivam de delegação da União, bem como acerca de sua limitação executória. Diga-se, enfim, que o poder de fiscalizar não é dos Estados em si, o que não lhes autoriza a instituir taxa.

Logo, respeitadas as características pertinentes à espécie taxa, apenas a União poderia criar tal espécie que vislumbrasse a fiscalização das atividades atinentes à lavra de hidrocarbonetos.

A despeito, o magistério de Paulsen (2014, p.79-82):

Assim é que só poderão ser instituídos tributos que possam ser reconduzidos a uma das normas concessivas de competência tributária, sob pena de inconstitucionalidade.

O exercício, por um ente político, de competência concedida constitucionalmente a outro implica invasão de competência. Cada qual deve circunscrever-se à competência que lhe foi outorgada, não podendo extrapolála.

(...)

Há tributos cuja competência é outorgada em função da atividade estatal. É o caso das taxas e das contribuições de melhoria.

Note-se que o art. 145, II, da CF cuida da cobrança de taxas pela União, pelos Estados, pelo Distrito Federal ou pelos Municípios, no âmbito de suas respectivas atribuições, de modo que cada ente federado tem competência para cobrar taxas pelos serviços que preste ou pelo poder de polícia que exerça no desempenho da sua competência administrativa.

\footnotetext{
s "Referimo-nos, em particular, às regras de competência legislativa pelas quais se haverá de pautar a regulamentação normativa, que é pressuposto para o exercício das competências materiais comuns. Ora, essas regras sinalizam no caso, para a preponderância da União. De fato, como se percebe pelo cotejo dos artigos 23 e 24 , as leis que servirão de embasamento para a execução das tarefas comuns serão, em sua maior parte, fruto de competência legislativa concorrente, em que caberá à União editar normas gerais e às demais esferas a legislação suplementar. Assim, por exemplo, tarefas como cuidar da saúde e da proteção dos deficientes; proteger o patrimônio cultural; proporcionar o acesso à cultura e à educação; proteger o meio ambiente; preservar florestas, a fauna e a flora, pressupõem a observância de normas gerais da União, com base no disposto nos incisos VI; VII; VIII; IX, XII e XIV do artigo 24 (...) Isto quando a competência material comum não se tiver de exercer de acordo com a lei federal editada no uso de competência legislativa privativa, hipótese em que a União estabelecerá normas gerais e específicas, legislando integralmente sobre a matéria" (g.n.) (ALMEIDA, 2007, p. 116-117).
} 
Assim, incabível a instituição de taxa de fiscalização quanto às atividades relacionadas à lavra de hidrocarbonetos por outros entes além da União.

\section{DO CONTROLE DE CONSTITUCIONALIDADE SOBRE AS LEIS ESTADUAIS FISCALIZATÓRIAS}

A despeito da possibilidade de ajuizamento de Ações Anulatórias em face dos respectivos entes estatais, com o cunho de tornar nulas, no caso concreto, as leis estaduais, temos que tal instrumento é de efeitos muito restritos. Da mesma forma o Mandado de Segurança, que precisará se curvar à obviedade de que são atacados atos concretos, mantendose a lei em vigência ainda que reconhecida a inconstitucionalidade da mesma na causa de pedir.

Muito mais palpável o ajuizamento de Ação Direta de Inconstitucionalidade, por um dos legitimados do artigo 103 da CF que podem ser provocados a tanto. Assim, por exemplo, a indústria interessada poderá apresentar representação junto à Procuradoria-Geral da República, ao Conselho Federal da Ordem dos Advogados ${ }^{t}$ ou à Presidência da República solicitando o ajuizamento da Ação e elencando as razões para tanto.

Nesse sentido, a Presidência da República ajuizou a Ação Direta de Inconstitucionalidade 4606 em face da Lei 10.850/2007, do Estado da Bahia, e do Decreto $11.736 / 2009$, que a regulamentou, por afronta aos artigos $1^{\circ}, 20$, VIII e IX e $\S 1^{\circ}, 21$, XII, “ $b$ ”, 22, IV e XII, 176 e 177. Pretendeu-se a inconstitucionalidade do referido Decreto por arrastamento (ADI 4606).

Tais atos normativos tinham o mesmo intuito de disciplinar a fiscalização, arrecadação e o controle das receitas decorrentes da exploração de recursos hídricos e minerais em seu território, isto é, na linha da temática aqui discutida.

\footnotetext{
t "O art. $2^{\circ}$, VII, da Lei n. 9.868/99 estabelece, em conformidade com o texto constitucional, que o Conselho Federal da OAB é legítimo para a propositura da ação direta de inconstitucionalidade. Trata-se de legitimidade dada em nítida atenção ao relevo jurídico-institucional do qual é dotado a OAB. O STF entende que a Ordem não necessita de demonstração da chamada pertinência temática para a legítima propositura da ação" (MENDES; STRECK, 2013, p.1413).
} 
Ainda é possível, a utilização de legitimado pelo conceito amplo de entidade de classe, que envolva, no caso, as empresas petrolíferas e de produção de gás natural, nos termos do precedente fixado no $\mathrm{AgRg}$ na ADI $3.153^{\mathrm{u}}$.

\section{CONCLUSÃO}

A presente análise comporta, como vimos, soluções em níveis diversos, a partir da compreensão de que o conceito de recursos minerais engloba ou não as atividades de petróleo e gás natural, mas, ao cabo, em nossa opinião, todas se direcionam à conclusão de inconstitucionalidade das leis estaduais que pretendem a fiscalização das participações governamentais.

Considerando-se o posicionamento mais substancial de que recursos minerais não englobam as atividades de petróleo e gás natural: i) Estados e Municípios não possuem competência fiscalizatória quanto às atividades de lavra de hidrocarbonetos, mas apenas de recursos minerais; ii) a competência para tanto é exclusiva da União, que a exerce por meio da ANP; iii) a ANP poderá estabelecer convênios com Estados e Distrito Federal - não com Municípios - apenas para facilitar atividades executórias de fiscalização, sem qualquer possibilidade de extensão do corpo fiscalizatório por estes entes.

Todavia, considerando-se que a terminologia recursos minerais abarca a exploração de petróleo e gás natural: i) apenas a União é competente para legislar sobre a temática; ii) a União poderá autorizar, por lei complementar, que Estados legislem acerca de temas específicos e em obediência estrita à legislação federal; iii) a possibilidade de fiscalização por parte dos Estados e Municípios não se coaduna com as atribuições constitucionais destes, salvo na hipótese do item ii, e, ainda assim, amarradas pelas diretrizes da legislação federal, não podendo os Estados inovar em tal temática; iv) por constituírem receitas decorrentes de transferência da

\footnotetext{
u "Entretanto, em decisão de 12.8.2004, o STF proveu o Agravo Regimental na ADIn n. 3.153-DF para dar seguimento à ação direta de inconstitucionalidade ajuizada pela Federação Nacional das Associações dos Produtores de Cachaça de Alambique (FENACA). Por oito voto a dois, o Plenário do Tribunal entendeu que a referida Federação teria legitimidade para a propositura da ação direta porque, apesar de composta por associações estaduais, poderia ser equiparada a uma entidade de classe. Desse modo, com base na peculiaridade de que a FENACA é entidade de classe que atua na defesa de categoria social, a Corte Constitucional reconheceu a legitimação excepcional dessa forma de associação". (MENDES; STRECK, 2013, p.1414).
} 
União, titular do bem, não estão os Estados autorizados a promover inscrição em dívida ativa, execução das quantias, suposições do quantum devido, bem como outras atividades indiretas para forçar os concessionários a aderirem ao valor que os Estados entendem como devidos; v) o canal legal para os Estados que entenderem que os valores estão sendo sonegados é a ANP, para requisitar documentos e também para explicitar suas razões, a fim de que esta tome as medidas cabíveis, a teor do artigo $8^{\circ}$ da Lei 9.478/97; vi) por ser a competência legislativa da União, proprietária do bem, apenas tal ente possui legitimidade para a instituição de possível taxa de fiscalização.

Além disso, em se tratando de competência da União - fiscalizatória - também lhe será a competência legislativa para instituir taxa pela fiscalização. Mesmo quando empresta parcela de seu poder aos Estados, mantém em si a competência, delegando meros atos executórios para fiel consecução dos objetivos legais. Diante disso, inconstitucionais também as tentativas dos Estados em instituir taxas fiscalizatórias de um poder que não lhe pertence.

Em ambos os casos, as leis estaduais que desafiam tais temáticas devem ser enfrentadas, como já o são em alguns casos, por Ação Direta de Inconstitucionalidade, no intuito de salvaguardar a força normativa da Constituição, protegendo-se suas competências das indevidas pretensões dos Estados-Membros. No mais, deve-se ter em mente que a proteção da Constituição parte do pressuposto de se estabelecer pacificação na interpretação constitucional, o que não ocorre quando as leis inconstitucionais são desafiadas em casos concretos, salvo na hipótese da ação incidental alcançar o Supremo Tribunal por meio de recurso extraordinário com repercussão geral, o que, de certa forma, demanda esforços muito maiores e dispêndio de tempo e processo.

\section{REFERÊNCIAS}

ALMEIDA, Fernanda Dias Menezes. Competências na Constituição de 1988. 4.ed. São Paulo: Atlas, 2007.

ATENCIO, Daniel. The discovery of new mineral species and type minerals from Brazil. Brazilian Journal of Geology. March, 2015.

BERCOVICI, Gilberto. Direito econômico do petróleo e dos recursos minerais. São Paulo: Quartier Latin, 2010. 
BUCHEB, José Alberto. Direito do petróleo: a regulação das atividades de exploração e produção de petróleo e gás natural no Brasil. Rio de Janeiro: Lumen Juris, 2007.

DI PIETRO, Maria Sylvia Zanella. Direito administrativo. São Paulo: Atlas, 2002.

GRAU, Eros. Comentários aos arts. 176 e 177. In: CANOTILHO, J. J. Gomes; MENDES, Gilmar Ferreira; SCARLET, Ingo Wolfgang; STRECK, Lenio Luiz (Coord.). Comentários à Constituição do Brasil. p.1851-1852. São Paulo/Coimbra: Saraiva, Almedina, 2013.

LEITE, Fabricio do Rozario Valle Dantas. As participações governamentais na indústria do petróleo sob a perspectiva do Estado-Membro. Revista DireitoGV, jul./dez. 2009.

MACHADO, Paulo Affonso Leme. Direito ambiental brasileiro. 16.ed. São Paulo: Malheiros, 2008.

MARQUES NETO, Floriano Azevedo. Bens públicos: função social e exploração econômica. Belo Horizonte: Fórum, 2010.

MAXIMILANO, Carlos. Hermenêutica e aplicação do direito. Rio de Janeiro: Forense, 1993.

MENDES, Gilmar Ferreira; COELHO, Inocêncio Mártires; BRANCO, Paulo Gustavo Gonet. Curso de direito constitucional. 3.ed. São Paulo: Saraiva, 2008.

; STRECK, Lenio Luiz. Comentários ao art. 103. In: CANOTILHO, J. J. Gomes; MENDES, Gilmar Ferreira; SCARLET, Ingo Wolfgang; STRECK, Lenio Luiz (Coord.). Comentários à Constituição do Brasil. São Paulo/Coimbra: Saraiva, Almedina, 2013.

MENEZELLO, Maria D’Assunção Costa. Comentários à lei do petróleo: lei federal no 9.478 , de 6-8.1997. São Paulo: Atlas, 2000.

OLIVEIRA, José Marcos Domingos de. Aspectos tributários do direito do petróleo - natureza jurídica das participações governamentais - government take. In: ROSADO, Marilda (Org.). Estudos e pareceres: direito do petróleo e do gás. Rio de Janeiro: Renovar, 2005.

OLIVEIRA, Régis Fernandes de. Curso de direito financeiro. São Paulo: Revista dos Tribunais, 2006.

PAULSEN, Leandro. Curso de direito tributário. 6.ed. Porto Alegre: Livraria do Advogado, 2014.

TAVARES, André Ramos. Curso de direito constitucional. 11.ed. São Paulo: Saraiva, 2013.

ULBRA, Universidade Luterana do Brasil. Museu de Ciências Naturais - Conceitos Minerais. Disponível em: <http://www.ulbra.br/mineralogia/conceito_minerais.htm>. Acesso em: 13 jul. 2015. 